\title{
Analisis Faktor Content Iklan Online Untuk Meningkatkan Profitabilitas Perusahaan Menggunakan Partial Least Square (Studi Kasus Pada OLX.CO.ID)
}

\author{
Husin Husin \\ Manajemen Informatika, Politeknik Negeri Jember, husin@polije.ac.id
}

Keywords:

Internet,

Online Advertisement,

Purchase intention,

Attitude Toward Brand,

Partial Least Square,

\begin{abstract}
The development of the Internet in this day and age is happening rapidly, including the lifestyle of consumers in meeting their daily needs. So that the internet as an advertising medium is based on the aspects of convenience and more benefits offered by the internet, namely the ease of information dissemination, wide reach, and easy access from consumers to advertisements on the internet. The purpose of this study is to examine and analyze the effect of judgment of online advertisement on attitude towards online advertisement, feelings of online advertisement on attitude towards online advertisement, attitude towards online advertisement towards attitude towards brand, and attitude towards brand towards purchase intention. The research method uses a quantitative approach, with the type of causal research. The data used in this study is primary data. The analysis technique used is Partial Least Square (PLS).
\end{abstract}

\begin{tabular}{l} 
Kata Kunci \\
\hline Internet, \\
Iklan Online, \\
Niat Beli, \\
Sikap Terhadap Merek, \\
Partial Least Square,
\end{tabular}

\section{ABSTRAK}

Perkembangan Internet di zaman sekarang ini terjadi dengan cepat termasuk didalamnya adalah gaya hidup konsumen dalam memenuhi kebutuhan sehari hari. Sehingga internet sebagai media periklanan didasarkan pada aspek kemudahan dan manfaat lebih yang ditawarkan internet, yaitu kemudahan penyebaran informasi, jangkauan yang luas, dan kemudahan akses dari konsumen terhadap iklan di internet. Tujuan penelitian ini untuk menguji dan menganalisis pengaruh dari judgment of online advertisement terhadap attitude towards online advertisement, feelings of online advertisement terhadap attitude towards online advertisement, attitude towards online advertisement terhadap attitude towards brand, dan attitude towards brand terhadap purchase intention. Metode penelitian menggunakan pendekatan kuantitatif, dengan jenis penelitian kausal. Data yang digunakan dalam penelitian ini adalah data primer. Teknik analisis yang digunakan adalah Partial Least Square (PLS).

\author{
Korespondensi Penulis: \\ Husin Husin, \\ Politeknik Negeri Jember, \\ J1. Mastrip PO BOX 164 Jember \\ Telepon: +6281338338833 \\ Email: husin@polije.ac.id
}

\section{PENDAHULUAN}

Perkembangan teknologi memberikan dampak yang signifikan terhadap berbagai aspek dalam kehidupan manusia. Salah satu dampak yang dapat dengan jelas dilihat adalah pada perubahan positif berupa peningkatan mediamedia yang digunakan untuk menyampaikan informasi, yaitu dengan menggunakan internet. Penggunaan internet memungkinkan proses penyampaian informasi yang lebih fleksikbel dengan daya jangkau yang jauh lebih luas daripada sebelumnya. Penggunaan internet sebagai media penyampai informasi telah dikembangkan menjadi salah satu instrumen yang dianggap paling efektif dalam pemasaran bisnis, yaitu sebagai media penyebaran iklan 
(advertising).[6] Periklanan menggunakan internet (online advertising) telah menjadi sumber informasi yang sangat penting bagi konsumen.[6] Hal tersebut didukung dengan semakin meningkatnya jumlah pengguna internet dari waktu ke waktu.

Pengguna internet di Indonesia pada tahun 2014 mengalami peningkatan sebesar 34,9\% dari tahun sebelumnya, dengan jumlah keseluruhan pengguna mencapai 88,1 juta orang. Jumlah tersebut meningkat kurang lebih sekitar 16,2 juta orang dari tahun sebelumnya yang hanya berjumlah sekitar 72 juta pengguna internet). [5] Penggunaan internet sebagai media periklanan didasarkan pada aspek kemudahan dan manfaat lebih yang ditawarkan internet, yaitu kemudahan penyebaran informasi, jangkauan yang luas, dan kemudahan akses dari konsumen terhadap iklan di internet.F Dengan demikian, tujuan utama dari iklan, yaitu untuk membentuk image atas suatu produk, perusahaan, atau objek apapun dari iklan [7], dapat lebih mudah dan lebih cepat terwujud.

Secara teoretis, iklan yang telah dilengkapi dengan fitur-fitur iklan, yaitu multimedia, pictures atau content, dapat memiliki efektivitas yang tinggi, namun demikian, pada praktiknya terdapat fenomena yang terkadang berbeda atau tidak sesuai dengan analogi teoretis tersebut, seperti yang terjadi pada iklan yang ditayangkan oleh objek penelitian ini, yaitu CV. XYZ, pada situs jual beli Olx.co.id. Content website OlX.co.id. juga mampu mendukung seluruh iklan yang diposting pada website tersebut, sehingga menambah daya tarik user dalam melihat dan memutuskan pembelian atas produk-produk yang di posting di website OlX.co.id. Berdasarkan fenomena tersebut, maka peneliti tertarik untuk meneliti efektivitas content iklan online CV. XYZ pada situs jual beli OlX.co.id. Analisa efektivitas content iklan online dalam penelitian ini akan dilakukan dengan menguji dan menganlisis pengaruh dari fitur iklan online CV. XYZ, yaitu content iklan online, terhadap niat beli konsumen. Analisis terhadap fitur iklan online sendiri bukan merupakan hal baru dalam bidang akademis. Hal tersebut disebabkan oleh peran dari iklan online yang telah menjadi salah kekuatan pemasaran terbesar dan sumber informasi utama bagi konsumen.[6]

Hasil penelitian wei dkk [7] tersebut mendukung analogi teoretis tentang peningkatan efektivitas iklan online melalui penambahan fitur-fitur pada iklan online. Analisis terhadap fitur iklan online sendiri bukan merupakan hal baru dalam bidang akademis. Hal tersebut disebabkan oleh peran dari iklan online yang telah menjadi salah kekuatan pemasaran terbesar dan sumber informasi utama bagi konsumen [6]. Berdasarkan keseluruhan penjelasan di atas, maka penelitian ini dilakukan untuk mengkaji efektivitas iklan online dengan menguji dan menganalisis pengaruh dari fitur content pada iklan online CV. XYZ pada situs jual beli online Olx.co.id.

Tujuan yang hendak dicapai dalam penelitian ini adalah Untuk menguji dan menganalisis pengaruh dari judgment of online advertisement terhadap attitude towards online advertisement. Selain itu untuk menguji dan menganalisis pengaruh dari feelings of online advertisement terhadap attitude towards online advertisement. Untuk menguji dan menganalisis pengaruh dari attitude towards online advertisement terhadap attitude towards brand. Dan tujuan dari penelitian ini adalah untuk menguji dan menganalisis pengaruh dari attitude towards brand terhadap purchase intention

\section{METODE PENELITIAN}

Penelitian ini menggunakan pendekatan kuantitatif. Jenis dari penelitian ini merupakan penelitian kausal. Data yang digunakan dalam penelitian ini menggunakan data primer. Sedangkan pengumpulan data dalam penelitian ini menggunakan kuesioner yang diukur dengan skala likert. Populasi yang digunakan dalam penelitian ini merupakan pengguna Olx.co.id dan sampel dipilih dengan metode non-probabillity sampling dengan menggunakan rumus: $\mathrm{n}=$ $\frac{\mathrm{Z}^{2} \cdot \mathrm{p}(1-\mathrm{p})}{\mathrm{E}^{2}}$. [1] Berdasarkan perhitungan dalam rumus tersebut, maka dapat diketahui bahwa sampel yang digunakan dalam penelitian ini adalah 68 sampel. Setelah data terkumpul langkah selanjutnya merupakan teknik analisis data dan uji hipotesis.

Teknik analisis data yang digunakan dalam penelitian ini adalah PLS. Berikut ini merupakan langkahlangkah analisis data menggunakan PLS menurut Ghozali [2] : 1) Merancang model struktural atau inner model, 2) Merancang model pengukuran atau outer model, 3) Mengkontruksi diagram jalur, 4) Mengkonversi diagram jalur ke sistem persamaan, 5) Melakukan estimasi atau pendugaan parameter, 6) Goodness of fit. Dalam hal ini dibagi menjadi dua yaitu outer model dan inner model, dan 7) Evaluasi Model. Pengujian hipotesis dalam penelitian ini dilakukan dengan melihat dari koefisien jalur yang ada dengan membandingkan antara nilai probabilitas 0,05 dengan nilai probabilitas Sig dengan dasar pengambilan keputusan Jika nilai probabilitas 0,05 lebih kecil atau sama dengan nilai probabilitas Sig atau $(0,05 \leq \mathrm{Sig})$ maka Ho diterima dan Ha ditolak, artinya tidak signifikan. Sebaliknya Jika nilai probabilitas 0,05 lebih besar atau sama dengan nilai probabilitas Sig atau (0,05 $\geq$ Sig) maka Ho ditolak dan Ha diterima, artinya signifikan.

\section{HASIL DAN ANALISIS}

Berdasarkan hasil penyebaran kuesioner diketahui bahwa jumlah responden adalah 68 dan representasi hasil jawaban yang diberikan oleh responden dapat dilihat dalam tabel berikut : 
Tabel 1. Tabel data kuisioner

\begin{tabular}{|c|c|c|c|c|c|c|c|c|}
\hline \multirow{2}{*}{ Indikator } & \multicolumn{5}{|c|}{ Skor Jawaban } & \multirow{2}{*}{ Total } & \multirow{2}{*}{ Skor } & \multirow{2}{*}{ Keterangan } \\
\hline & 1 & 2 & 3 & 4 & 5 & & & \\
\hline Judgment of Online Advertisement & 0 & 0 & 84 & 272 & 52 & 68 & 3.92 & Baik \\
\hline Feeling of Online Advertisement & 0 & 0 & 70 & 163 & 39 & 68 & 3.89 & Baik \\
\hline Attitude towards Online Advertisements & 0 & 2 & 67 & 176 & 27 & 68 & 3.84 & Baik \\
\hline Atittude towards brands & 0 & 2 & 92 & 155 & 23 & 68 & 3.73 & Baik \\
\hline Purchase Intention & 0 & 1 & 92 & 263 & 52 & 68 & 3.90 & Baik \\
\hline
\end{tabular}

Berdasarkan tabel data kuisioner diatas mengenai Judgment of Online Advertisement Hal tersebut ditunjukkan dengan banyaknya responden yang memberikan bahwa konsumen percaya pada iklan yang di posting di Website OLX dan konsumen dapat mencari informasi atas barang dan jasa melalui fitur searching pada konten Website OLX. Hasil mengenai Feeling of Online Advertisement menunjukkan bahwa hal tersebut membuktikan bahwa bahwa konsumen merasa Website OLX memberikan manfaat ganda kepada dirinya. Sedangkan hasil mengenai Attitude towards Online Advertisements, hasil tersebut menunjukkan bahwa konsumen dapat mengubungi seluruh pemasang iklan di Website OLX untuk melakukan transaksi secara langsung. Dan untuk variabel Atittude towards brands, berdasarkan hasil pengumpulan kuesioner menunjukkan bahwa konsumen lebih suka mencari produk atau jasa yang diiklankan di Website OLX karena kredibiltas websitenya, Sedangkan hasil dari pengumpulan kuesioner mengenai Purchase Intention, menunjukkan bahwa konsumen selalu berkeinginan untuk selalu mencari kebutuhan barang atau jasa di Website OLX,

Langkah awal untuk memeriksa apakah indikator-indikator yang digunakan untuk mengolah data dapat dikatakan reliable adalah dengan melakukan uji reliabilitas tahap awal dengan menggunakan indicator reliablity. Dari hasil analisis data pada variabel Judgment of Online Advertisement $\left(\mathrm{X}_{1}\right)$, sebagian besar indikator memiliki tingkat reliabilitas yang cukup baik, untuk variabel Feeling of Online Advertisement $\left(\mathrm{X}_{2}\right)$, sebagian besar indikator memiliki tingkat reliabilitas yang baik. Sedangkan variabel Attitude towards Online Advertisements $\left(\mathrm{Z}_{1}\right)$, sebagian besar indikator memiliki tingkat reliabilitas yang baik. Dan untuk variabel Atittude towards brands $\left(\mathrm{Z}_{2}\right)$, sebagian besar indikator memiliki tingkat reliabilitas yang baik. Variabel Purchase Intention (Y), sebagian besar indikator memiliki tingkat reliabilitas yang baik. Pada tahap kedua pengukuran reliabilitas, dilakukan pengukuran internal consistency reliability untuk mengukur seberapa konsisten indikator tiap-tiap variabel yang ada. dari hasil analisis data menunjukkan bahwa keseluruhan variabel memiliki nilai composite reliability diatas 0,6 , sehingga dapat disimpulkan bahwa keseluruhan variabel memiliki level internal consistency reliability yang tinggi. Setelah analisis data untuk mengetahui reliabilitas selanjutnya yaitu menganalisis untuk mengetahui validitas data, dari hasil analisis data menunjukkan bahwa semua variabel memiliki convergent validity yang layak.

Selanjutnya untuk mengetahui seberapa besar pengaruh yang diberikan variabel independen terhadap variabel dependen dalam penelitian ini maka digunakan evaluasi path coefficient. Berikut merupakan hasil uji Path Coefficient dan Coefficient of Determination $\left(\mathrm{R}^{2}\right)$. Dari gambar dibawah ini dapat dijelaskan bahwa nilai path coefficient terbesar ditunjukkan dari pengaruh Atittude towards brands $\left(\mathrm{Z}_{2}\right)$ terhadap Purchase Intention (Y) sebesar 47,024. Pengaruh Feeling of Online Advertisement $\left(\mathrm{X}_{2}\right)$ terhadap Attitude towards Online Advertisements $\left(\mathrm{Z}_{1}\right)$ sebesar 4,338. Pengaruh Attitude towards Online Advertisements $\left(\mathrm{Z}_{1}\right)$ terhadap Atittude towards brands $\left(\mathrm{Z}_{2}\right)$ sebesar 3,369 dan pengaruh judgment of Online Advertisement $\left(\mathrm{X}_{1}\right)$ terhadap Attitude towards Online Advertisements $\left(\mathrm{Z}_{1}\right)$ sebesar0,814

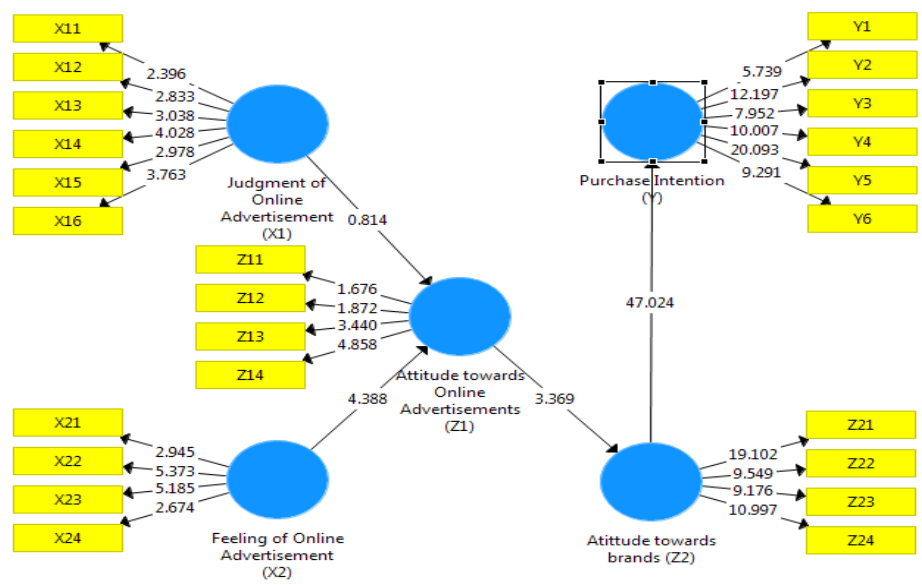

Gambar 1. Hasil Uji Path Coefficient dan Coefficient of Determination $\left(\mathrm{R}^{2}\right)$ 
Selain itu, dapat dilihat pula bahwa keseluruhan variabel dalam model ini memiliki path coefficient dengan angka yang positif. Artinya, jika semakin besar nilai path coefficient pada satu variabel independenterhadap variabel dependen, maka semakin kuat juga pengaruh antara variabel independenterhadap variabel dependen tersebut. Namun pengaruh judgment of Online Advertisement $\left(\mathrm{X}_{1}\right)$ terhadap Attitude towards Online Advertisements $\left(\mathrm{Z}_{1}\right)$ secara langsung memiliki angka yang paling rendah, yaitu 0,814 . Sementara itu, nilai coefficient of determination $\left(\mathrm{R}^{2}\right)$ dapat dilihat dari tabel di bawah ini:

Tabel 2. Hasil Uji $R^{2}$

\begin{tabular}{ccc}
\hline Variabel & Nilai $\mathrm{R}^{2}$ & Prosentase \\
\hline Atittude towards brands $\left(\mathrm{Z}_{2}\right)$ & 0,163 & $16,3 \%$ \\
Attitude towards Online & 0,246 & $24,6 \%$ \\
Advertisements $\left(\mathrm{Z}_{1}\right)$ & 0,782 & $78,2 \%$ \\
Purchase Intention $(\mathrm{Y})$ & \\
\hline
\end{tabular}

Pada tabel diatas, membuktikan bahwa variabel Purchase Intention (Y)dipengaruhi oleh variabel Atittude towards brands $\left(\mathrm{Z}_{2}\right)$ dengan nilai varian sebesar 0,782 atau 78,2\% menjadi pengaruh yang paling besar dalam penelitian ini. Artinya, sebanyak 21,8\% lainnya dipengaruhi oleh variabel lain diluar penelitian. Nilai T-statistics diperoleh dari prosedur bootstrapping, dimana nilai ini digunakan untuk menarik kesimpulan pada uji hipotesis. Nilai T-statistics dengan level signifikansi 5\% menjelaskan bahwa inner model akan signifikan jika nilai T-statistics lebih besar dari 1,96. Berikut ini merupakan hasil yang menunjukkan T-statistic dan uji hipotesis

Tabel 3. Hasil T-statistics dan Uji Hipotesis

\begin{tabular}{|c|c|c|c|c|c|}
\hline & Original Sample (0) & Sample Mean (M) & Standard Error (STERR) & TStatistics (|O/STERR) & PValues \\
\hline Atittude towards brands (Z2) $\rightarrow>$ Purchasse Intention (M) & 0.884 & 0.888 & 0.019 & 47,024 & 0,000 \\
\hline Attitude towards Online Advertisements (Z1) $\rightarrow$ Atittude towards brands (Z2) & .0 .403 & -0.421 & 0.120 & 3,369 & 0.001 \\
\hline Feeling of Online Advertisement (XZ) -> Attitude towards Online Advertisements (Z1) & 0.453 & 0.459 & 0.103 & 4,388 & 0.000 \\
\hline Judgment of Online Advertisement (XI) - A Attitude towards Online Advertisements (Z1) & .0108 & .0 .186 & 0.132 & 0.814 & 0.416 \\
\hline
\end{tabular}

Dengan melihat Tabel 2, dapat diartikan bahwa nilai original sample (O) adalah nilai path coefficient yang menunjukkan kekuatan pengaruh dari satu latent variable ke satu latent variable lainnya. Sedangkan nilai pada kolom sample mean (M) menunjukkan nilai tengah dari path coefficient. Sedangkan standard deviation (STDEV) dan standarderror (STDERR), menunjukkan nilai simpang dan error pada sampel mean. Nilai T statistics untuk melihat nilai $\mathrm{T}$ hitung yang akan digunakan untuk pengujian hipotesis.

Mengacu pada tabel tersebut maka dapat diketahui bahwa hipotesis yang menyatakan bahwa:

1. Judgment of Online Advertisements berpengaruh positif signifikan terhadap Attitude towards Online Advertisementstidak dapat terbukti kebenarannya dilihat dari nilai T-Statistic 0,814 dengan nilai probabilitas 0,416 .

2. Feelings of Online Advertisements berpengaruh positif signifikan terhadap Attitude towards Online Advertisementsdapat terbukti kebenarannya dilihat dari nilai T-Statistic4,388 dengan nilai probabilitas 0,000 .

3. Attitude towards Online Advertisements berpengaruh positifsignifikan terhadap Attitude towards brandsdapat terbukti kebenarannya dilihat dari nilai T-Statistic 3,369 dengan nilai probabilitas 0,001.

4. Attitude towards brands berpengaruh positifsignifikan Purchase Intentiondapat terbukti kebenarannya dilihat dari nilai T-Statistic 47,024 dengan nilai probabilitas 0,000 .

\section{Pembahasan}

\section{Pengaruh Judgment of Online Advertisements terhadap Attitude towards Online Advertisements}

Berdasarkan hasil pengujian diperoleh hasil bahwa variabel Judgment of Online Advertisements tidak terbukti berpengaruh positif dan signifikan terhadap Attitude towards Online Advertisements bila dilihat dari besarnya nilai TStatistic 0,814 dengan nilai probabilitas 0,416. Hal tersebut menunjukkan bahwa Judgment merupakan komponen kognitif merujuk pada pengetahuan, kepercayaan, dan opini dari konsumen tentang objek sikap, yaitu objek yang menjadi fokus utama perlakuan atau sikap. Komponen kognitif dari konsumen meliputi pengetahuan dan persepsi konsumen yang didapatkan dari kombinasi pengalaman langsung dengan objek sikap dan informasi yang berkaitan dari berbagai sumber.

Menurut Wei dkk.[7], komponen kognitif dari sikap konsumen menghasilkan suatu bentuk penilaian terhadap suatu objek (judgment), dimana penilaian tersebut didasarkan pada kepercayaan konsumen terhadap atribut yang dimiliki objek dan konsekuensi atau hasil yang mungkin didapatkan akibat perilaku tertentu terhadap objek tersebut. Dalam konteks penelitian ini, komponen kognitif dari sikap konsumen diteliti berkaitan dengan perikalanan online 
(online advertiesements) yang tentunya tidak akan memberikan perubahan yang signifikan terhadap sikap konsumen terhadap suatu objek konsumen tersebut tidak memiliki pengetahuan yang kuat pada suatu objek yang diamatinya.

\section{Pengaruh Feelings of Online Advertisements terhadap Attitude towards Online Advertisements}

Berdasarkan hasil pengujian diperoleh hasil bahwa variabel Feelings of Online Advertisements terbukti berpengaruh positif dan signifikan terhadap Attitude towards Online Advertisements bila dilihat dari besarnya nilai TStatistic 4,388 dengan nilai probabilitas 0,000. Hal tersebut menggambarkan bahwa komponen afektif dari sikap merefleksikan perasaan (feelings), evaluasi, atau emosi berkaitan dengan objek sikap. Komponen afektif menjelaskan apa yang dirasakan konsumen terhadap objek sikap. Dengan demikian, komponen afektif berkaitan dengan konten emosional dan rasa suka atau tidak suka atas objek tertentu.

Menurut Wei dkk.[7] ketika seorang konsumen berinteraksi dengan stimuli maka pada diri konsumen tersebut akan muncul suatu bentuk perasaan (feelings) terhadap stimuli tersebut. Dengan demikian, komponen afektif berkaitan dengan konten emosional dan rasa suka atau tidak suka atas objek tertentu. Menurut Wei dkk.[7] ketika seorang konsumen berinteraksi dengan stimuli maka pada diri konsumen tersebut akan muncul suatu bentuk perasaan (feelings) terhadap stimuli tersebut. Perasaan tersebut dapat berupa rasa suka, terganggu, atau bingung. Dalam penelitian ini, komponen afektif dari sikap konsumen akan diteliti berkaitan dengan online advertisement sebagai objek sikap. Untuk itu, apabila secara emosional seorang konsumen merasa sangat tertaik dan terkesan pada Website dan konsten-konten iklan yang diposting di OLX, maka sikap yang akan ditampakkan oleh konsumen akan semakin nyata dan positif pada objek tersebut.

\section{Pengaruh Attitude towards Online Advertisementsterhadap Attitude towards brands}

Berdasarkan hasil pengujian diperoleh hasil bahwa variabel Attitude towards Online Advertisements terbukti berpengaruh positif dan signifikan terhadap Attitude towards brands bila dilihat dari besarnya nilai T-Statistic3,369 dengan nilai probabilitas 0,001. Hal tersebut menunjukkan bahwa Atittude towards brandsakan muncul ketika seorang konsumen berinteraksi dengan suatu produk dengan merek tertentu. Interaksi tersebut seringkali terjadi atau difasilitasi oleh adanya periklanan (advertising), yang menyajikan dan menyampaikan mengenai produk dengan karakteristik dan merek tertentu kepada konsumen [2]. Mendukung pernyataan tersebut, [7] menyatakan bahwa sikap konsumen terhadap merek (atittude towards brands) dipengaruhi oleh sikap konsumen terhadap periklanan (attitude toward advertising).[4]

Atittude towards brands terbentuk oleh pengalaman konsumen ketika berinteraksi dengan merek suatu produk dalam jangka waktu yang lama, dimana interaksi tersebut menghasilkan perasaan pada diri konsumen. Jika konsumen merasa bahwa apa yang diharapkan dapat terpenuhi oleh produk dengan merek tersebut, maka konsumen akan merasa puas. Sebaliknya, jika konsumen merasa bahwa apa yang diharapkan dapat terpenuhi oleh produk dengan merek tersebut, maka konsumen akan merasa puas. Sebaliknya, jika konsumen merasa bahwa keinginan atau kebutuhannya tidak dapat terpenuhi setelah membeli dan menggunakan produk dengan merek tertentu, maka konsumen akan merasa kecewa atau tidak puas.

\section{Pengaruh Attitude towards brandsterhadap Purchase Intention}

Berdasarkan hasil pengujian diperoleh hasil bahwa variabel Attitude towards brands terbukti berpengaruh positif dan signifikan terhadap Purchase Intention bila dilihat dari besarnya nilai T-Statistic 47,024 dengan nilai probabilitas 0,000. Menurut Ghorban [2], atittude towards brands dipahami sebagai hasil dari evaluasi menyeluruh yang dilakukan konsumen terhadap merek dari suatu produk. Hal tersebut disebabkan karena purchase intention ditentukan juga oleh sikap konsumen terhadap merek dari barang yang hendak dibeli (atittude towards brands). Dalam memilih suatu merek, konsumen melakukan evaluasi dengan membandingkan beberapa merek yang memenuhi kriteria dan dirasa dapat memenuhi kebutuhan dan keinginan konsumen. Menurut Ghorban [2] , atittude towards brands dipahami sebagai hasil dari evaluasi menyeluruh yang dilakukan konsumen terhadap merek dari suatu produk. Atittude towards brands dapat berupa sikap yang negatif atau positif, yang berlangsung dalam waktu yang lama, kecuali konsumen mendapatkan pengalaman baru yang memberikan pengaruh dan merubah atittude towards brands pada konsumen

Atittude towards brands dapat berupa sikap yang negatif atau positif, yang berlangsung dalam waktu yang lama, kecuali konsumen mendapatkan pengalaman baru yang memberikan pengaruh dan merubah atittude towards brands pada konsumen. Atittude towards brands terbentuk oleh pengalaman konsumen ketika berinteraksi dengan merek suatu produk dalam jangka waktu yang lama, dimana interaksi tersebut menghasilkan perasaan pada diri konsumen. Jika konsumen merasa bahwa apa yang diharapkan dapat terpenuhi oleh produk dengan merek tersebut, maka konsumen akan merasa puas. Sebaliknya, jika konsumen merasa bahwa keinginan atau kebutuhannya tidak dapat terpenuhi setelah membeli dan menggunakan produk dengan merek tertentu, maka konsumen akan merasa kecewa atau tidak puas. 


\section{KESIMPULAN}

Kesimpulan hasil penelitian dapat disajikan sebagai berikut:

1. Judgment of Online Advertisements tidak terbukti berpengaruh positif signifikan terhadap Attitude towards Online Advertisements dilihat dari nilai T-Statistic 0,814 dengan nilai probabilitas 0,416.

2. Feelings of Online Advertisements terbukti berpengaruh positif signifikan terhadap Attitude towards Online Advertisements dilihat dari nilai T-Statistic 4,388 dengan nilai probabilitas 0,000.

3. Attitude towards Online Advertisements terbukti berpengaruh positif signifikan terhadap Attitude towards brands dilihat dari nilai T-Statistic 3,369 dengan nilai probabilitas 0,001 .

4. Attitude towards brands terbukti berpengaruh positif signifikan Purchase Intention dilihat dari nilai T-Statistic 47,024 dengan nilai probabilitas 0,000 .

Saran yang dapat diberikan adalah sebagai berikut:

1. Diharapkan hasil penelitian ini dapat bermanfaat bagi civitas akademis sebagai tambahan referensi penelitian tentang Judgment of Online Advertisements, Attitude towards Online Advertisements, Feelings of Online Advertisements, Attitude towards brandsdan Purchase Intention, sehingga dapat memperluas wawasan dan pengetahuan serta sebagai dasar perbandingan sejauh mana teori-teori yang diperoleh selama kuliah, sehingga dapat diketahui relevansi teori dengan kondisi yang ada di lapangan.

2. Diharapkan penelitian ini dapat digunakan oleh pihak provider website sebagai wacana dalam melihat prospek dari kegiatan pemasaran yang berbasis online, sebagai pertimbangan dalam menentukan strategi pemasaran berikutnya mengingat semakin berkembangnya pemasaran berbasis online.

\section{UCAPAN TERIMA KASIH}

Ucapan terima kasih dapat diperuntukkan kepada pihak-pihak yang telah membantu dalam penelitian, perusahaan dan instansi yang menjadi objek penelitian, dan juga kepada pihak yang membantu dalam publikasi artikel.

\section{REFERENSI}

[1] Eriyanto. (2007). Teknik Sampling Analisis Opini Publik . Yogyakarta: LKiS.

[2] Ghorban, Z. S. (2012). Brand Attitudes, Its Antecedents And Consequences. Investigation Into Smartphone Brands In Malaysia. Journal Of Business And Management, Vol. 2, Issue 3, July-Aug., 31-35

[3] Ghozali, Imam. (2011). Aplikasi Analisis Multivariat dengan Program SPSS. Badan Penerbit Universitas Diponegoro, Semarang

[4] Glass, Haydan et.al. (2014). The Value Of Internet Services to New Zealand Businesses. Sapere Research Group.

[5] H. Husin, W. Dewanto, P. Destarianto, and G. Murti, "Analysis of Online Advertising Content on Purchase Decision in Marketplace,” Proc. - 2019 Int. Conf. Comput. Sci. Inf. Technol. Electr. Eng. ICOMITEE 2019, vol. 1, pp. 59-64, 2019, doi: 10.1109/ICOMITEE.2019.8921198.

[6] Peter, O. R., Martin, O., \& Lilly, N. (2014). The Moderating Effect Of Subjective Norms, Perceived Behavioral Control And Gender On The Relationship Between Attitude Towards Internet Advertising And Puchase Intention Of University Students In Kenya. European Journal Of Business Management, Vol. 2, Issue 1, 1-37.

[7] Wei, K. K., Jerome, T., \& Shan, L. W. (2010). Online Advertising: A Study Of Malaysian Consumers. International Journal Of Business And Information, Vol. 5, No. 2, December, 111-134 